\title{
DLC COATINGS IN THE REGENERATION OF PARTS OF COMMON RAIL FUEL INJECTION SYSTEMS
}

\author{
Damian HADRYŚ, Andrzej KUBIK, Zbigniew STANIK \\ Silesian University of Technology, Faculty of Transport, Katowice, Poland, EU, damian.hadrys@polsl.pl \\ https://doi.org/10.37904/metal.2019.898
}

\begin{abstract}
Diamond-like-carbon coatings (DLC) have exceptional chemical, protective and tribological properties. They are increasingly used in industry. DLC coatings are characterized by high hardness, resistance to chemical agents and low coefficient of friction and it is a reason to check of its use in tribological pair cooperation in automotive means of transport.

The main goal of the article is to determined tribological parameters of DLC layers and to check the possibility of its using for the regeneration of injector elements for the self-ignition engine, which is the injector needle in Common Rail system. This component is responsible for proper operation of the injector (opening and closing) and is made as a precision pair with a injector socket. The injector needle cooperates with the socket in a reciprocating manner, which leads to the wear of these elements and appearance of seizures. Fuel quality is also an important issue.

Currently, DLC layers are used in industry, but their application in the processes of regeneration of precision parts in means of automotive transport is rather marginal.

The article presents the results of tribological studies of DLC layers used as regeneration layers for self-ignition engines injectors in Common Rail system. On the basis of the obtained test results, it can be concluded that the use of DLC coating on the surface of selected parts of cooperating injectors in the Common Rail system will allow for longer life.
\end{abstract}

Keywords: DLC layers, injector of self-ignition engine, wear, regeneration, tribological studies

\section{INTRODUCTION}

The most important challenges for today's state of technical knowledge are issues related to materials, connection of components and wear. Research is being carried out on all these fields, both in the laboratory and in the operational field [1-3].

Self-ignition engines are still a popular for mode of transportation (especially for delivery vehicles and trucks) as well as heavy work machines. A very important accessory for these engines is the fuel supply system (diesel oil). The Common Rail system is now widely used.

Injectors of this system work in very difficult conditions (high temperature, high fuel pressure). In addition, the injector precision pairs are sensitive to low quality fuel (e.g. with water content) and insufficient filtration. These types of circumstances favor the accelerated consumption of the injector's precision pairs.

Generally, it is possible to repair injectors by exchanging their precision pairs. However, attempts are done to regenerate the injector parts by applying DLC coatings.

This article presents the results of tribological tests of specimens corresponding to precise injector pair, both without DLC coating and with DLC coating.

\section{TRIBOLOGICAL WEAR}

The frictional force appears on the contact surface of the cooperating parts and causes rising of temperature. This leads to overheating and gouging of the material and destruction of parts. Friction between parts also 
leads to chipping of material, formation of filings and pollen, contributing largely to the creation of wear. Tribological wear is a chronic problem in every field of technology. Its effects annually exclude periodically or completely from operation hundreds of mechanisms [4].

Tribological wear is a phenomenon causes by friction processes. This is manifested by a change in the properties and physical structures of friction surfaces and mass loss. The intensity of wear depends on many factors and external influences, such as: value of friction force, lubrication, abrasion resistance of material and its hardness.

The phenomenon of abrasive wear occurs during contact between two surfaces. Wear is favored by surface irregularities resulting from inaccurate machining. However, the shapes of the parts themselves are not always responsible for this type of tribological wear. It is worth mentioning that abrasive particles and wear products that appear as a result of wear are also conducive to wear. The abrasive itself often appears as particles suspended in the lubricating liquid (for example as a result of insufficient filtration) or as a result of oxidation of the parts material [5].

\section{DLC COATINGS}

Carbon based materials form a vast and constantly developing group of materials. They have a wide spectrum of properties and applications. Coal can take a large number of stable forms, mainly due to its ability to form various hybridized bonds. One of the hardest varieties are DLC coatings (Diamond-Like Carbon). Thin DLC coatings were first made in 1970 [6].

Coatings are interesting solution in terms of abrasive wear protection. Use of DLC coatings is one of the most popular example of an abrasion resistant coating on the surface of friction pair components. These coatings are a combination with very high hardness corresponding to the diamond and with very low friction coefficient corresponding to graphite. It was shown in Figure 1. Properties of these coatings cause that they are increasingly used in medicine and industry.

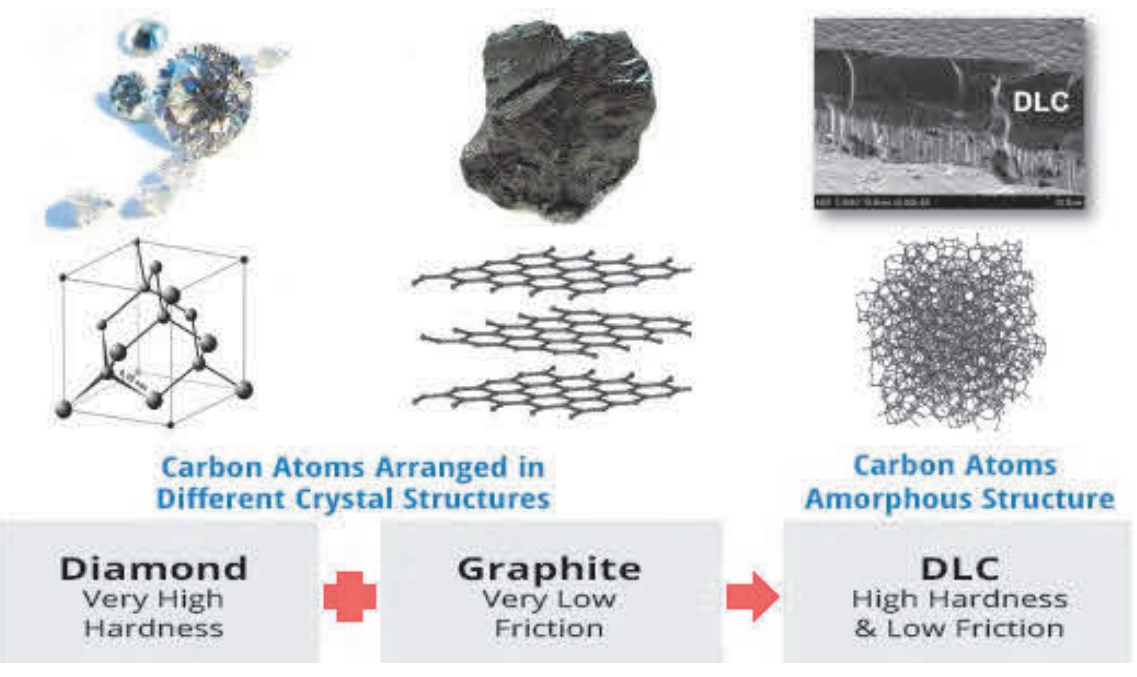

Figure 1 Combination of diamond, graphite and DLC properties and structure [7]

DLC coatings are characterized by passivity, chemical stability and resistance to chemical agents, high hardness, special resistance to abrasive and tribological wear, low value of friction coefficient, thermal conductivity, low coefficient of thermal expansion, high elasticity index and fracture toughness. All these features meet the expectations of the constructors and, to a large extent, solve the problem of seizure the parts. This leads to longer life of the DLC coated parts and significantly reduces the number of machine failures [8-11]. 
It is worth mentioning that DLC coatings can be made on the base material in various ways. Examples include sputtering techniques, pulsating laser deposition and the use of ion or plasma beams.

\section{TEST STAND AND EXPERIMENTAL PROCEDURE}

The planned studies were of comparative nature. The tests were carried out according to the same assumptions and test conditions for all specimens and counterspecimens (Table 1).

Table 1 Investigation conditions [own study]

\begin{tabular}{|c|c|}
\hline Parameter & Value / Description \\
\hline Rotational speed & $100 \mathrm{~min}^{-1}$ \\
\hline Load & $10 \mathrm{~N}$ \\
\hline Testing time & $3 \mathrm{~h}$ \\
\hline Initial and final lubrication liquid temperature & $262 \mathrm{~K}$ and $280 \div 292 \mathrm{~K}$ \\
\hline Lubrication conditions & $\begin{array}{c}\text { Immersion lubrication with standard liqiud } \\
\text { used to carry out final inspection of injectors on test stands }\end{array}$ \\
\hline
\end{tabular}

The investigations have been carried out on a T-05 roll-block tribological tester (Figure $2 \mathbf{a}$ ). The possibilities offered by the tester include setting of parameters such as: roller rotation speed, friction path or exact number of rotations, lubricating liquid temperature, load. Figure $\mathbf{2 b}$ presents shapes of specimen and counterspecimen used during investigation.
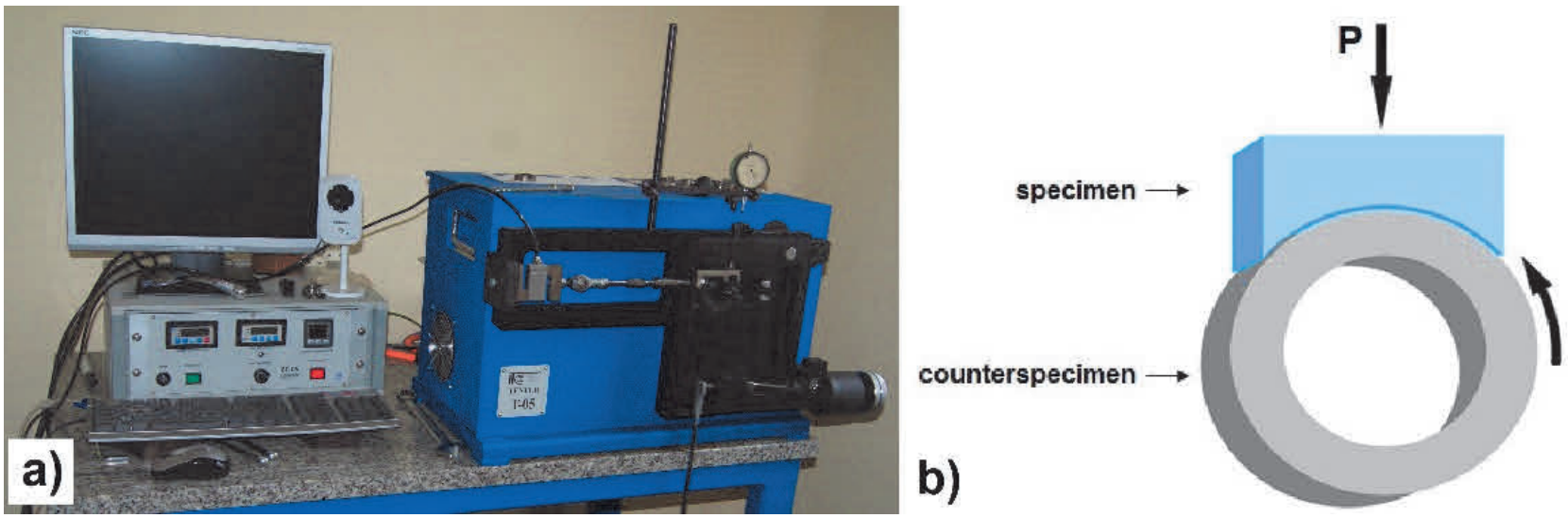

Figure 2 Test stand - tribological tester T-05 (a) and specimen and counterspecimen (b) used during investigation [own study]

All specimens and counterspecimens have been made with $17 \mathrm{HNM}$ steel. This steel had following mechanical properties: yield stress $830 \mathrm{MPa}$, tensile strength $1180 \div 1420 \mathrm{MPa}$ and elongation $\mathrm{A}_{5} 7 \%$. Chemical composition of this material was shown in Table 2.

In next step a half of all number of specimens and counterspecimens was directed to coating process. In this way following parts were prepared for investigations:

- $\quad$ specimens (block) made by 17HNM steel,

- $\quad$ specimens (block) made by 17HNM steel with DLC coating,

- counterspecimens (roll) made by 17HNM steel,

- $\quad$ counterspecimens (roll) made by $17 \mathrm{HNM}$ steel with DLC coating. 
Table 2 Chemical composition of 17HNM steel [12]

\begin{tabular}{|c|c|c|c|c|c|c|c|c|c|c|c|c|}
\hline Element & C & $\mathrm{Mn}$ & $\mathrm{Si}$ & $\mathrm{P}$ & $S$ & $\mathrm{Cr}$ & $\mathrm{Ni}$ & Mo & W & $\mathrm{V}$ & Co & $\mathrm{Cu}$ \\
\hline Amount, \% & $\begin{array}{c}0.14 \\
\div \\
0.19\end{array}$ & $\begin{array}{c}0.4 \\
\div \\
0.7\end{array}$ & $\begin{array}{c}0.17 \\
\div \\
1.37\end{array}$ & $\begin{array}{c}\max \\
0.035\end{array}$ & $\begin{array}{c}\max \\
0.035\end{array}$ & $\begin{array}{c}1.5 \\
\div \\
1.8\end{array}$ & $\begin{array}{c}1.4 \\
\div \\
1.7\end{array}$ & $\begin{array}{c}0.25 \\
\div \\
0.35\end{array}$ & $\begin{array}{l}\max \\
0.05\end{array}$ & $<0.2$ & - & $\begin{array}{c}\max \\
0.3\end{array}$ \\
\hline
\end{tabular}

During the tests, the specimens rotated at a constant preset speed $\left(100 \mathrm{~min}^{-1}\right)$. The counterspecimen was pressed against the specimen with a specific force $(10 \mathrm{~N})$. The friction pair was lubricated in an immersion way using a standard liquid for performing the final inspection of the injectors on test stands. One study lasted 3 hours.

\section{RESULTS AND DISCUSSION}

Different kinds of specimen and counterspecimen (with and without DLC coating) were tested and compared. The investigations have been carried out with the same assumptions and test conditions. The results show the average and standard deviation of the five tests. Figure 3 presents example of specimen and counterspecimen without and with DLC coating after investigations. On the surfaces of friction, signs of wear were observed. The dominant mechanism of wear is abrasive wear with elements of adhesion (tacking). Abrasive wear was observed with numerous scratch was observed. Cracks appear after local damage of the DLC coating. However, abrasive wear products can cause scratching of surfaces. In addition, wear products can stick to the top layer of the part.
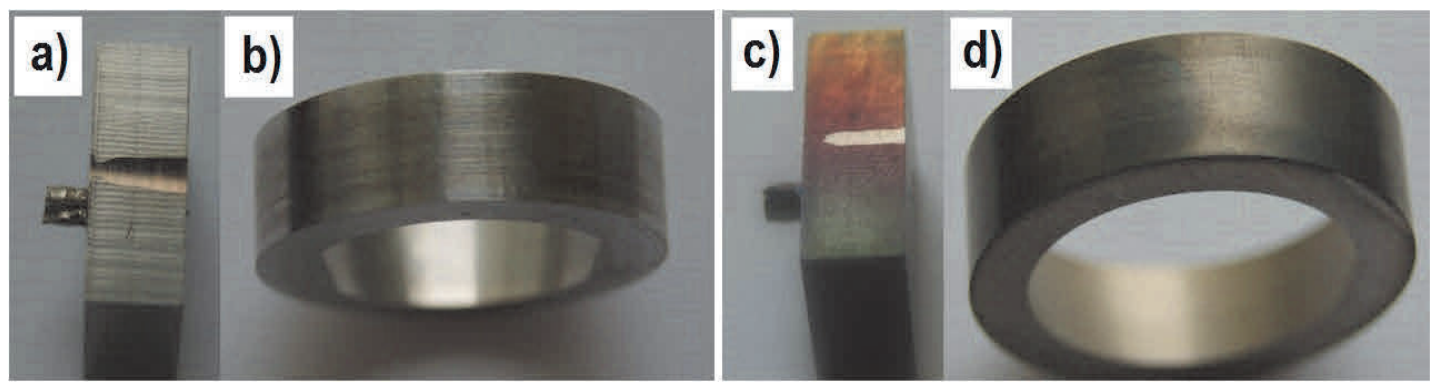

Figure 3 Example of specimen (a) and counterspecimen (b) without DLC coating after test and example of specimen (c) and counterspecimen (d) with DLC coating after test [own study]

Moreover, the initial lubrication liquid temperature was $262 \mathrm{~K}$. During testing this temperature was rising and the final temperature of the lubricating liquid was greater than the initial temperature. For specimen and counterspecimen without DLC coating, the final temperature was $292 \mathrm{~K}$. For the specimen and counterspecimen with a DLC coating, the final temperature was $280 \mathrm{~K}$. This indicates that the friction phenomenon was less intense during testing parts with DLC coatings (less heat was released).

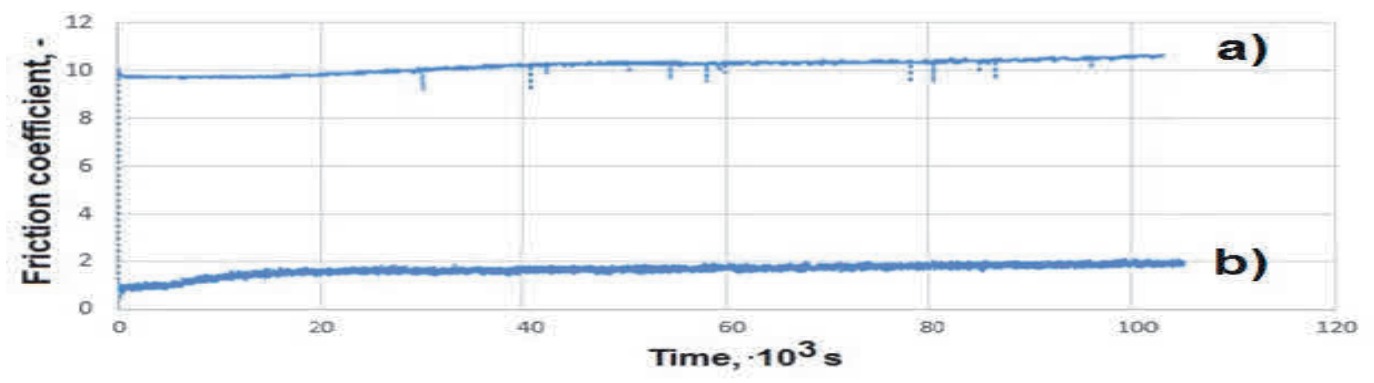

Figure 4 Example of changes of friction coefficient during tribological tests for tribological pair without DLC coating (a) and with DLC coating (b) [own study] 
Figure 4 presents example of changes of friction coefficient during tribological tests for tribological pair without DLC and with DLC. Value of friction coefficient of tribological pair without DLC coating was about 9.8 at the beginning of test. This value was rising slowly to about 10.4 at the end of test. While value of friction coefficient of tribological pair with DLC coating was about 0.9 at the beginning of test. In first part of test value of this parameter was rising rather quickly but form about 20 second of testing to the end of test value of friction coefficient was rising slowly to about 2.0. When comparing the test results, it should be noted that the value of the coefficient of friction was more than five times lower for the part with DLC coatings then for parts without these coatings.

Table 3 presents results obtaining during measurement of mass of specimens for specimens without DLC coating and with DLC coating, while Table 4 presents results obtaining during measurement of mass of counter specimens for counterspecimens without DLC coating and with DLC coating.

Table 3 Results obtaining during measurement of mass of specimens [own study]

\begin{tabular}{|c|c|c|c|c|c|c|}
\hline \multirow{2}{*}{ No. } & \multicolumn{2}{|c|}{$\begin{array}{c}\text { Mass } \\
\text { of specimen } \\
\end{array}$} & \begin{tabular}{c} 
without DLC coating, g \\
\cline { 2 - 7 }
\end{tabular} & \multicolumn{2}{c|}{$\begin{array}{c}\text { Mass } \\
\text { of specimen } \\
\text { with DLC coating, g }\end{array}$} & \multicolumn{2}{c|}{$\begin{array}{c}\text { Difference in mass of specimens } \\
\text { before and after tribological tests, g }\end{array}$} \\
\hline $\mathbf{1}$ & 8.3727 & 8.3726 & 8.3830 & 8.3831 & 0.0001 & with DLC coating \\
\hline $\mathbf{2}$ & 8.3726 & 8.3720 & 8.3830 & 8.3829 & 0.0006 & 0.0001 \\
\hline $\mathbf{3}$ & 8.3726 & 8.3698 & 8.3831 & 8.3831 & 0.0028 & 0.0001 \\
\hline $\mathbf{4}$ & 8.3726 & 8.3698 & 8.3829 & 8.3830 & 0.0028 & -0.0001 \\
\hline $\mathbf{5}$ & 8.3726 & $8, .3702$ & 8.3830 & 8.3829 & 0.0024 & 0.0001 \\
\hline Average & 8.372620 & 8.370880 & 8.383000 & 8.383000 & 0.001740 & 0.000000 \\
\hline $\begin{array}{l}\text { Standard } \\
\text { deviation }\end{array}$ & 0.000045 & 0.001324 & 0.000071 & 0.000100 & 0.001292 & 0.000100 \\
\hline
\end{tabular}

It should be noted that the difference between the average specimen mass without a DCL coating before and after the test was $0.001740 \mathrm{~g}$ (minimum difference $0.0001 \mathrm{~g}$, maximum difference $0.0028 \mathrm{~g}$ ). However, the difference between the average mass of the specimen with the DCL coating before and after the test was 0.0 $\mathrm{g}$ (minimum difference $-0.0001 \mathrm{~g}$, maximum difference $0.0001 \mathrm{~g}$ ). This indicates that the smaller mass difference applies to specimens with DLC coatings - they present lower wear. It is worth mentioning about cases in which a slight increase in the mass of the specimens after the test was observed. This can be explained by the migration of the DLC layer from counterspecimen to specimen. This phenomenon is described in the literature [13-16].

Table 4 Results obtaining during measurement of mass of counterspecimens [own study]

\begin{tabular}{|c|c|c|c|c|c|c|}
\hline \multirow{2}{*}{ No. } & \multicolumn{2}{|c|}{$\begin{array}{c}\text { Mass } \\
\text { of counterspecimen } \\
\text { without DLC coating, g }\end{array}$} & \multicolumn{2}{c|}{$\begin{array}{c}\text { Mass } \\
\text { of counterspecimen } \\
\text { with DLC coating, g }\end{array}$} & \multicolumn{2}{c|}{$\begin{array}{c}\text { Difference in mass of counterspecimens } \\
\text { before and after tribological tests, g }\end{array}$} \\
\cline { 2 - 7 } & before test & after test & before test & after test & without DLC coating & with DLC coating \\
\hline $\mathbf{1}$ & 22.9256 & 22.9135 & 22.9500 & 22.9498 & 0.0121 & 0.0002 \\
\hline $\mathbf{2}$ & 22.9241 & 22.9140 & 22.9503 & 22.9496 & 0.0101 & 0.0007 \\
\hline $\mathbf{3}$ & 22.9215 & 22.9137 & 22.9501 & 22.9498 & 0.0078 & 0.0003 \\
\hline $\mathbf{4}$ & 22.9169 & 22.9137 & 22.9502 & 22.9500 & 0.0032 & 0.0002 \\
\hline $\mathbf{5}$ & 22.9169 & 22.9136 & 22.9500 & 22.9498 & 0.0033 & 0.0002 \\
\hline Average & 22.921000 & 22.913700 & 22.950120 & 22.949800 & 0.007300 & 0.000320 \\
\hline $\begin{array}{l}\text { Standard } \\
\text { deviation }\end{array}$ & 0.004020 & 0.000187 & 0.000130 & 0.000141 & 0.003998 & 0.000217 \\
\hline
\end{tabular}


It should be noted that the difference between the average counterspecimens mass without a DCL coating before and after the test was $0.0073 \mathrm{~g}$ (minimum difference $0.0032 \mathrm{~g}$, maximum difference $0.0121 \mathrm{~g}$ ). However, the difference between the average mass of the counterspecimens with the DCL coating before and after the test was $0.000320 \mathrm{~g}$ (minimum difference $0.0002 \mathrm{~g}$, maximum difference $0.0007 \mathrm{~g}$ ). This indicates that the smaller mass difference applies to counterspecimens with DLC coatings - they present lower wear.

\section{CONCLUSION}

It was observed that using of DLC coatings influences positively on reduction of wear of specimens and counterspecimens. Wear was smaller for specimens and counterspecimens with DLC coatings then for specimens and counterspecimens without DLC coatings. Rising of lubricant temperature was smaller for parts with DLC coatings - it is a proof about smaller friction parameters. Mass loss was smaller for parts with DLC coatings. Value of friction coefficient was about 5 times smaller for parts with DLC coatings then for parts without DLC coatings.

\section{REFERENCES}

[1] HADRYS, D.: Mechanical properties of plug welds after micro-jet cooling, Archives of Metallurgy And Materials, 2016, 4 (61).

[2] BAKOWSKI, H.: Wear mechanism of spheroidal cast iron piston ring-aluminum matrix composite cylinder liner contact, Archives of Metallurgy and Materials, 2018, 1 (63).

[3] HADRYS, D., WEGRZYN, T., PIWNIK, J.: Plastic properties of fine-grained WMD after micro-jet cooling, Archives of Metallurgy And Materials, 2014, 3 (59).

[4] HADRYS, D.: Welding with micro-jet cooling as a way to improve of mechanical properties of mode of transportation shaft surface. Transport Problems, 2018,4.

[5] CHRONOWSKA-PRZYWARA, K., KOT, M., ZIMOWSKI, S.: The research techniques for analysis of mechanical and tribological properties of coating-substrate systems, Scientific Journal of Silesian University of Technology. Series Transport, 2014, 83 (1904).

[6] POTRYKUS, J. Poradnik mechanika. REA, 2009. p. 422.

[7] OZIMINA, D., MADEJ, M., KOWALCZYK, J., SUCHANEK, J., TATICEK, F., KOLARIIKOVA, M.: The wear performance of diamond-like carbon coatings in relation to coating composition and friction pair, Tribologia, 2012, 3.

[8] HEF USA Company. [viewed 2019-03-09]. Available from: http://www.hefusa.net/pvd_coating/DLC-coatings.html.

[9] DRÁBIK, M., TRUCHLÝ, M., BALLO, V., ROCH, T, KVETKOVÁ, L., KÚŠ, P.: Influence of substrate material and its plasma pretreatment on adhesion and properties of WC/a-C:H nanocomposite coatings deposited at low temperature, Surface \& Coatings Technology, 2018, 333.

[10] MARCINIAK, J., PASZENDA, Z., WALKE, W., BASIAGA M., SMOLIK, J.: DLC coatings on martensitic steel used for surgical instruments, Archives of Materials Science and Engineering, 2007, 5 (28).

[11] MADEJ, M., OZIMINA, D.: The tribological properties of DLC coatings, Tribologia, 2012, 3.

[12] Catalog of steel. The Multuserwis Company. 2 p. [viewed 2019-03-09]. Available from: www.multistal.pl.

[13] PIĄTKOWSKA, A.: The effect of the DLC layer thickness on the tribological properties in sliding friction, Tribologia, 2012, 3.

[14] TYAGI, A., WALIA, R. S., MURTAZA, Q., PANDEY, S. M., TYAGI, P. K., BAJAJ, B.: A critical review of diamond like carbon coating for wear resistance applications, International Journal of Refractory Metals and Hard Materials, 2019, 78.

[15] LOVE, C. A., COOK, R. B., HARVEY, T., DEARNLEY, P., WOOD, R.: Diamond like carbon coatings for potential application in biological implants - A review, Tribology International, 2013, 63.

[16] NURUZZAMAN, D. M.,, CHOWDHURY, M. A., NAKAJIMA, A., RAHAMAN, M. L., KARIM, S. M. I.: Friction and wear of diamond like carbon (DLC) coatings - a review, Recent Patents on Mechanical Engineering, 2011, 1 (4). 